\title{
Pulmonary function and maximal transrespiratory pressures in ankylosing spondylitis
}

\author{
D VANDERSCHUEREN ${ }^{1}$ M DECRAMER ${ }^{2}$ P VAN DEN DAELE, ${ }^{1}$ \\ AND J DEQUEKER ${ }^{1}$
}

From the ${ }^{1}$ Division of Rheumatology and the ${ }^{2}$ Respiratory Division, Department of Internal Medicine $K U$ Leuven, Belgium

SUMMARY Clinical measurements and pulmonary functions, including maximal transrespiratory pressures, were studied in 30 patients (age 43 (SD 10) years) with ankylosing spondylitis. Vital capacity (VC) was slightly reduced to $79(16) \%$ and forced expiratory volume in one second $\mathrm{N}^{\leftarrow}$ $\left(\mathrm{FEV}_{1}\right)$ was similarly reduced to $82(20) \%$ such that the average $\mathrm{FEV}_{1} / \mathrm{VC}$ ratio was $77 \cdot 8(6 \cdot 65)$. 은 Total lung capacity was slightly reduced to $85(13) \%$. Transfer factor of the lung for carbon monoxide (TLCO) averaged 88 (17)\% and TLCo per unit lung volume was 114 (26)\%. Reductions in lung volumes correlated well with clinical measurements. Both maximal expiratory pressures $\left(\mathrm{PE}_{\max }\right)$ and inspiratory pressures $\left(\mathrm{PI}_{\max }\right)$ were clearly reduced to $56(17) \%$ and $76(28) \%$ respectively. This suggests that spirometrically determined volumes were better preserved than respiratory muscle strength in ankylosing spondylitis. It is speculated that the reduction in respiratory muscle strength may be due to intercostal muscle atrophy.

Ankylosing spondylitis is a systemic rheumatic disease. Involvement of the lungs with a reduction in lung volumes is a well known manifestation of this disease, presumably resulting from a reduction in thoracic mobility. ${ }^{1}$ No data are available, however, on respiratory muscle strength in patients with ankylosing spondylitis.

This study was designed to evaluate respiratory muscle function and strength by measurement of the maximal transrespiratory pressures as well as lung volumes in ankylosing spondylitis.

\section{Patients and methods}

We examined 30 patients meeting the criteria of definite ankylosing spondylitis according to the American Rheumatism Association (New York). Table 1 shows their clinical features. The following clinical measurements were obtained by one observer: expansion in centimetres at the level of axilla, nipple, diaphragm, and umbilicus; Schöber index; and fingertop to floor distance (Table 2).

All patients underwent routine spirometry and determination of residual volume using a helium

Accepted for publication 16 November 1988 .

Correspondence to Dr D Vanderschueren, Division of Rheumatology, Department of Internal Medicine, Catholic University of Leuven, UZ Pellenberg, B-3041 Pellenberg, Belgium.
Table 1 Clinical data of the patients*

\begin{tabular}{ll}
\hline & Mean (SD) \\
\hline Age (years) & $43(9 \cdot 8)$ \\
Weight $(\mathrm{kg})$ & $74 \cdot 6(14 \cdot 3)$ \\
Height $(\mathrm{cm})$ & $1 \cdot 69(7 \cdot 3)$ \\
Age at onset of symptoms (years) & $28 \cdot 2(9)$ \\
Age at onset of treatment (years) & $34 \cdot 3(9 \cdot 8)$ \\
Difference between age at onset & \\
and age at start of treatment (years) & $6(6 \cdot 6)$
\end{tabular}

*The patients comprised 25 men, four women; $M: F=6 \cdot 25: 1$.

dilution technique. Transfer factor of the lung for $\frac{D}{0}$ carbon monoxide was measured with a single breath test and related to the normal values of Billiet $e t a .^{2}$ o Maximal airway pressures were measured as described previously. ${ }^{3}$ Briefly, we used a mercury manometer connected to a stiff rubber mouth piece (external diameter $3 \mathrm{~cm}$ ) without leaks. Pressures were sustained for two seconds. Subjects wore a noseclip while the measurements were made.

Maximal expiratory pressures $\left(\mathrm{PE}_{\max }\right)$ were measured at total lung capacity (TLC) and functional residual capacity (FRC), inspiratory pressure $\left(\mathrm{PI}_{\max }\right)$ at residual volume $(\mathrm{RV})$ and FRC. In $\stackrel{\stackrel{\mathrm{P}}{\mathbb{Q}}}{\mathrm{Q}}$ addition, for inspiratory pressures the subject was $\varrho$ instructed to make an inspiratory effort with the 
Table 2 Expansions, fingertop to floor distance, and Schöber index

\begin{tabular}{lccc}
\hline & $\begin{array}{l}\text { Mean }(S D) \\
(\mathrm{cm})\end{array}$ & $\begin{array}{l}\text { Minimum } \\
\text { mean value } \\
(\mathrm{cm})\end{array}$ & $\begin{array}{l}\text { Maximum } \\
\text { mean value } \\
(\mathrm{cm})\end{array}$ \\
\hline Expansion at the level of axilla & $3 \cdot 24 \quad(2 \cdot 10)$ & $-0 \cdot 2$ & 7 \\
Expansion at the level of nipple & $3 \cdot 75(2 \cdot 40)$ & $-1 \cdot 5$ & 9 \\
Expansion at the level of diaphragm & $3 \cdot 79(2 \cdot 08)$ & 0 & $7 \cdot 5$ \\
Expansion at the level of umbilicus & $4 \cdot 12 \quad(2 \cdot 2)$ & $1 \cdot 5$ & 9 \\
Fingertop to floor distance & $19 \cdot 50(14 \cdot 4)$ & 0 & $50 \cdot 5$ \\
Schöber index & $3 \cdot 44(1 \cdot 66)$ & 0 & $6 \cdot 5$ \\
\hline
\end{tabular}

thorax and not to use the cheeks, thus avoiding glottis closure and pressure generation by the cheeks alone. Maximal pressures were expressed as a percentage of the predicted values determined by a similar technique as described previously. ${ }^{4}$

\section{Results}

\section{S P I R O M E T R Y}

A slight reduction in spirometrically determined lung volumes was present. Vital capacity (VC): 79

Table 3 Pulmonary function results indicated in litres and as a percentage of the predicted values

\begin{tabular}{|c|c|c|}
\hline & Mean $(S D)$ & $\begin{array}{l}\text { Mean }(S D) \\
(\%)\end{array}$ \\
\hline VC (litres) & $3.87(1.08)$ & $79.4(16 \cdot 0)$ \\
\hline $\mathrm{FEV}_{1}$ (litres) & $3.04(0.98)$ & $82 \cdot 2(20 \cdot 0)$ \\
\hline $\mathrm{FEV}_{1} / \mathrm{VC}$ & $0.78(0.07)$ & \\
\hline RV (litres) & $1.52(0.46)$ & $97.7(27.4)$ \\
\hline TLC (litres) & $5.62(1.15)$ & $85 \cdot 0(12.7)$ \\
\hline RV/TLC & $0.28(0.08)$ & \\
\hline TLco (ml/mm Hg.min) & $28 \cdot 54(6 \cdot 68)$ & $87 \cdot 8$ (17) \\
\hline $\begin{array}{l}\text { Teco per unit lung volume } \\
(\mathrm{ml} / \mathrm{mm} \mathrm{Hg} \cdot \mathrm{min})\end{array}$ & $6.97(1.18)$ & $114(25 \cdot 6)$ \\
\hline
\end{tabular}

$\mathrm{VC}=$ vital capacity; $\mathrm{FEV}_{1}=$ forced expiratory volume in one second; $\mathrm{RV}=$ residual volume; $\mathrm{TLC}=$ total lung capacity; $\mathrm{TLCO}=$ transfer factor of the lung for carbon monoxide.
(16)\% (3.87 (1.08 litres), total lung capacity (TLC): $85(13) \%(5 \cdot 62)(1.15)$ litres, and forced expiratory volume in one second $\left(\mathrm{FEV}_{1}\right): 82(20) \%(3.04$ $(0.98)$ litres) were similarly reduced. Residual volume (RV) $(97.7(27.4) \%$ of predicted or 1.52 $(0.46)$ litres) was normal and as a consequence the RV/TLC ratio $(0.28)$ was slightly increased. The transfer factor of the lung for carbon monoxide (TLCo) (88 (17)\% of predicted) slightly decreased but the TLco per unit lung volume slightly increased (114 (26)\%). Table 3 summarises these results.

\section{RELATION BETWEEN CLINICAL}

MEASUREMENTS AND SPIROMETRY

Clinical measurements (Table 2) correlated with pulmonary function tests (Table 3 ). The best correlations were observed between vital capacity and chest expansion $(p<0.001)$, followed by the correlation between vital capacity and Schöber index $(p<0 \cdot 01)$. A good inverse relation between vital capacity and fingertip to floor distance was present $(\mathrm{p}<0.01)$. We noticed, however, that patients with a markedly reduced thorax expansion (14 mm or less) still had a vital capacity that was $62 \%$ of predicted values. Table 4 summarises these correlations. Table 5 summarises the relation between thorax expansion and lung volumes.

MAXIMAL TRANSRESPIRATORY PRESSURES Maximal transrespiratory pressures were significantly

Table 4 Summary of regression coefficients

\begin{tabular}{|c|c|c|c|c|c|c|c|}
\hline & $V C$ & $F E V_{l}$ & $T L C$ & $R V$ & $T L C O / L V$ & $\begin{array}{l}\text { Fingertip } \\
\text { to floor } \\
\text { distance }\end{array}$ & $\begin{array}{l}\text { Schöber } \\
\text { index }\end{array}$ \\
\hline Expansion at the level of axilla & 0.62 & $0 \cdot 60$ & $0 \cdot 65$ & $0 \cdot 22$ & -0.38 & -0.35 & $0 \cdot 60$ \\
\hline Expansion at the level of nipple & 0.65 & $0 \cdot 64$ & $0 \cdot 66$ & $0 \cdot 17$ & -0.47 & -0.34 & $0 \cdot 56$ \\
\hline Expansion at the level of diaphragm & $0 \cdot 53$ & $0 \cdot 53$ & 0.61 & $0 \cdot 32$ & -0.42 & $-0 \cdot 13$ & $0 \cdot 50$ \\
\hline Expansion at the level of umbilicus & -0.38 & $-0 \cdot 33$ & $-0 \cdot 33$ & 0.02 & $0 \cdot 31$ & 0.42 & $-0 \cdot 23$ \\
\hline Fingertop to floor distance & -0.43 & -0.435 & -0.33 & 0.08 & $0 \cdot 20$ & - & -0.42 \\
\hline Schöber index & 0.61 & $0 \cdot 58$ & 0.44 & $-0 \cdot 21$ & -0.37 & $-0 \cdot 42$ & - \\
\hline
\end{tabular}

$\mathrm{VC}=$ vital capacity $\mathrm{FEV}_{1}=$ forced expiratory volume in one second; $\mathrm{RV}=$ residual volume; $\mathrm{TLC}=$ total lung capacity; TLCo=transfer factor of the lung for carbon monoxide; $\mathrm{LV}=$ lung volume. 
Table 5 Mean (SD) pulmonary function values expressed as percentage of predicted value for different excursions at the nipple level. Values are mean (SD)

\begin{tabular}{|c|c|c|c|c|}
\hline $\begin{array}{l}\text { Thorax } \\
\text { expansion } \\
(\mathrm{mm})\end{array}$ & $V C^{*}$ & $F E V_{I}$ & $T L C$ & $T L C O / L V$ \\
\hline $\begin{array}{l}\text { Correlation } \\
<14 \\
14-62\end{array}$ & $\begin{array}{l}0.65 \\
62.33(8 \cdot 62) \\
77.45(15 \cdot 53)\end{array}$ & $\begin{array}{l}0.64 \\
62(8 \cdot 8) \\
79 \cdot 65(19 \cdot 76)\end{array}$ & $\begin{array}{l}0 \cdot 66 \\
74(9 \cdot 17) \\
80 \cdot 65(11 \cdot 38)\end{array}$ & $\begin{array}{l}-0 \cdot 47 \\
137(23 \cdot 26) \\
115 \cdot 2(26 \cdot 89)\end{array}$ \\
\hline$>62$ & $94.67(5 \cdot 16)$ & $100.83(7.52)$ & $99.83(6.18)$ & $99.67(11.78)$ \\
\hline
\end{tabular}

${ }^{*}$ For abbreviations see Table 4.

Table 6 Maximal transrespiratory pressures. Values are mean $(S D)$

\begin{tabular}{lc}
\hline & $\begin{array}{c}\text { Mean }(\mathrm{SD}) \\
\left(\mathrm{cmH}_{2} \mathrm{O}\right)\end{array}$ \\
\hline PE at TLC & $110.5(36.8)($ or $56(17) \%$ of predicted values) \\
PE at FRC & $92.0(30 \cdot 8)$ \\
PI at FRC & $-75 \cdot 1(29.4)$ \\
PI at RV & $-88.6(32.5)$ (or 76 (28)\% of predicted values) \\
\hline
\end{tabular}

$\mathrm{PE}=$ expiratory pressure; TLC=total lung capacity; $\mathrm{FRC}=$ functional residual capacity; $\mathrm{PI}=$ inspiratory pressure; $\mathrm{RV}=$ residual volume.

reduced: mean (SD) $\mathrm{PE}$ at TLC averaged $110 \cdot 5$ $(36.8) \mathrm{cm} \mathrm{H}_{2} \mathrm{O}$ and PE at FRC averaged $92.0(30.8)$ $\mathrm{cm} \mathrm{H}_{2} \mathrm{O}$; PI at FRC averaged $-75 \cdot 1(29.4) \mathrm{cm} \mathrm{H}_{2} \mathrm{O}$ and $\mathrm{PI}$ at $\mathrm{RV}-88.6(32.5) \mathrm{cm} \mathrm{H}_{2} \mathrm{O}$. If these results are related to normal values according to sex and age this means that $\mathrm{PI}_{\max }(\mathrm{PI}$ at $\mathrm{RV}$ ) was reduced to $76(28) \%$ and $\mathrm{PE}_{\max }$ (PE at TLC) was reduced to 56 (17)\%. Twenty seven of 30 patients had a $P E_{\max }$ value of two standard deviations or more below the mean; 16 of 30 patients had a $\mathrm{PI}_{\max }$ value of two standard deviations or more below the mean according to the normal values of Rochester and Arora. ${ }^{\overline{4}}$ Table 6 summarises these results.

\section{Discussion}

In agreement with previous studies, ${ }^{5-10}$ the present study shows that patients with ankylosing spondylitis have minimal restrictive pulmonary defects, the most pronounced abnormality being a reduction in vital capacity. Moreover, there was no evidence of air flow obstruction. In previous studies no important changes in pulmonary compliance could be shown. ${ }^{5}$ Furthermore, we found good correlations between pulmonary function tests and clinical measurements, especially the correlation between vital capacity and thorax expansion together with the correlation between vital capacity and Schöber index. These correlations are similar to those found in other studies. ${ }^{679}$

These correlations between vital capacity and thorax expansion of Schöber index may be affected by variability in spinal mobility and chest expansion ${ }_{\infty}^{\infty}$ as these vary with age and sex, and, moreover, mayos be influenced by artefacts related to measurement techniques. ${ }^{11} 12$ These artefacts were minimised by measuring chest wall expansion while the patient stood with hands on head, and arms flexed in frontal plane.

Unexpectedly, however, patients with ankylosing? spondylitis with a markedly reduced thorax expan $\overrightarrow{0}$ sion (less than $14 \mathrm{~mm}$ ) still had an average vitapo capacity of $62 \%$ of the predicted value. This could either mean that the diaphragm contributes theo greatest part to vital capacity or that it partlys compensates for the loss of thoracic expansion. The latter phenomenon is certainly present during tidap breathing as it is a-common clinical observation tha? patients with ankylosing spondylitis have enhanced $\overrightarrow{\vec{b}}$ inspiratory abdominal outward motion. Previous 3 studies have suggested that the diaphragmatic con tribution to inhaled volume increases as a direct consequence of ankylosis of the thoracic cage. $568913-150$ The compensatory effort of the diaphragm is a probable explanation of the fact that patients with ankylosing spondylitis have only mild respiratoryo discomfort or none at all. We have occasionally noticed that patients with ankylosing spondylitis with unilateral diaphragmatic paralysis have pronounced dyspnoea together with a marked reduction of the vital capacity.

It is known that other deformities, such aș kyphoscoliosis, are usually accompanied by moren severe abnormalities of lung function. ${ }^{4}$ This isN probably partly due to the presence of thoracic $\omega$ deformity and may be partly due to other factors such as fixation changes of the thorax in ankylosinge spondylitis at a lung volume higher than thees relaxation volume of the thorax. ${ }^{68}$ Necropsy studies of patients with ankylosing spondylitis would be most interesting to determine whether or not these $\mathbb{0}$ patients show hypertrophy of the diaphragm.

Thus the observed reduction of vital capacity is $\varrho$ probably the result of two opposing influences: the 
rigidity and reduced expansion of the thoracic cage and the compensatory effort of the diaphragm. The reduction of vital capacity appears to be only slightly affected or not influenced at all by the treatment or duration of the disease. ${ }^{69}$

Finally, this study shows that patients with ankylosing spondylitis have clearly reduced maximal transrespiratory pressures, ${ }^{34}$ indicating decreased respiratory muscle strength. If indeed the diaphragmatic strength were to be unchanged or even increased, as follows from the reasoning developed above, the decreased respiratory muscle strength would be due to reduced strength or atrophy of intercostal or accessory muscles, or both. Although the present data do not provide direct evidence of intercostal muscle atrophy and do not allow us to conclude why such atrophy may be present, it is tempting to speculate that immobilisation of these muscles due to thoracic rigidity and decreased inspiratory intercostal and accessory activation leading to disuse may be an important factor contributing to it.

\section{References}

1 Rosenow E, Strimlan C V, Muhm J R, Ferguson R H. Pleuropulmonary manifestations of ankylosing spondylitis. Mayo Clin Proc 1977; 52: 641-9.

2 Billiet L, Barsien W, Naedts J. Effet de taille, du sex et de l'âge sur la capacité de diffusion pulmonaire de l'adulte normal. Physiologie Paris 1963; 55: 194-200.

3 Decramer M, Demedts M, Rochette F, Billiet L. Maximal transrespiratory pressures in obstructive lung disease. Bull Eur Physiopathol Respir 1980; 16: 479-80.

4 Rochester D F, Arora N S. Respiratory muscle failure. Med Clin North Am 1983; 67: 573-99.

5 Stewart R M, Ridyard J B, Pearson J D. Regional lung function in ankylosing spondylitis. Thorax 1976; 31: 433-6.

6 Josenhans W T, Wang C S, Josenhans G, et al. Diaphragmatic contributions to ventilation in patients with ankylosing spondylitis. Respiration 1971; 28: 331-46.

7 Feltelius N, Hedenström H, Hillerdal G, Hällgren R. Pulmonary involvement in ankylosing spondylitis. Ann Rheum Dis 1986; 45: 736-40.

8 Gacad G, Hamosh P. The lung in ankylosing spondylitis. Am Rev Respir Dis 1973; 107: 286-9.

9 Franssen M J A M, Van Herwaarden C L A, van de Putte L B A, et al., Lung function in patients with ankylosing spondylitis. A study of the influence of disease activity and treatment with non steroidal anti-inflammatory drugs. Disease activity and response to therapy in ankylosing spondylitis. Nijmegen: Stichting studentenpers, 1985. (Thesis.)

10 Hart F D, Emerson P A, Gregg I. Thorax in ankylosing spondylitis. Ann Rheum Dis 1963; 22: 11-18.

11 Moll J M H, Wright V. Normal range of spinal mobility. Ann Rheum Dis 1971; 30: 381-6.

12 Moll J M H, Wright V. An objective clinical study of chest expansion. Ann Rheum Dis 1972; 31: 1-8.

13 Grimby G, Fighl Meyer A R, Blomstrand A. Portioning of the contributions of ribcage and abdomen to ventilation in ankylosing spondylitis. Thorax 1974; 29: 179-84.

14 Davis D. Ankylosing spondylitis and lung fibrosis. $Q \mathrm{~J}$ Med 1972; 41: 407.

15 Zorab PA. The lungs in AS. $Q J$ Med 1962; 31: 272-3. 